\title{
SEISMIC ANALYSIS AND COMPARISON BETWEEN MONOLITHIC RC STRUCTURE BARE AND MASONRY STRUCTURE
}

\author{
Santhosh H B ${ }^{1}$, D.Prakash ${ }^{2}$, Naveen Kumar ${ }^{3}$ \\ ${ }^{1}$ Pursuing MTech, GCE Ramanagaram \\ ${ }^{2}$ Associate Professor, GCE Ramanagaram \\ ${ }^{3}$ Assistant Professor, PESCE Mandya
}

\begin{abstract}
Earthquake is a sudden energy release in the upper mantle or earth's crust, usually caused by volcanic activity or a fault plane movement and resulting in the generation of destructive seismic waves. In the present work performance of $3 D$ frames under different lateral load resisting system has been evaluated by pushover analysis. Different lateral load resisting systems like masonary infill and RCC infills have been evaluated. Also linear static and dynamic analysis have been performed and evaluate the results like storey shear, base shear, storey drift, time period etc., have been compared. A frame with RCC infill will perform good among all the types.
\end{abstract}

Keywords: Seismic Analysis, Modal Investigation, Equivalent Static Analysis, Pushover Analysis.

\section{INTRODUCTION}

The ground motion during earth quake will be of complex nature due to factors like source effect, path effect and local site effect. Structures supported on ground will be subjected to vibration due to ground motion caused by earthquake. Thus the dynamic loading on the structure during earthquake is by the motion of supports, not an external loading. The various factors contributing to the structural damage during earthquake are vertical irregularities, irregularity in strength and stiffness, mass irregularity, torsional irregularity etc.

Earthquakes are natural disasters of a generally unpredictable nature. Duration of earthquake is usually rather short, lasting from few seconds to more than a minute or so. Usually one or more major peaks of magnitude of motion are recorded during a quake. These peaks represent the maximum effect of the quake. The critical effect on the structure will be predicted by the ground movements at the location of the structure, even though the effect of the quake is measured in terms of the energy release at the location of the ground fault.

\subsection{Modal Investigation}

In the circumstance of dynamics of structure, investigation of modal is explained as the collection of various methods, whose main point is characterization of dynamic buildings of engineering. Even though helpful as a hypothetical instrument to get the system's response by means of a source-obtain method, the uses are generally interconnected to an testing atmosphere. now, a method is recognize (characterized) from assessing its reaction beneath a identified excited state, in a essentially a invert lane of theoretical method.

Modal investigation from engineering approach has developed significantly from past 50 years. This development is been rushed by calculation leaps of current decades and the progress of tough evaluating tools. Its achievement is importantly due to a easy engineering method merged with a tough geometrical base, which show linear systematic model. Exactly, the superposition of modal theorem has become a basis in the investigation of straight method, leaving a virtual difficult thing to be disintegrated into less significant and convenient structural block. In area of investigation of linear modal, this theorem is frequently concerned to a multi-degree-of-freedom method to disintegrate into more separate single-degree-of-freedom systems, all completely secretarial for the performance of a particular method of a original structure.

\subsection{Equivalent Static Analysis}

The reaction of a building to seismic activity - generated forces is a vigorous process. instantly, a real appraisal of the design forces is got by vigorous examination of the structure model. even though it has been recognized lonely vigorous examination is used occassional in custom model, because of such examination it consumes a lot of time and it is difficulty.

\subsection{Pushover Analysis}

Pushover procedure can offer a significant insight into the weak links in earthquake performance of a building. A range of iterations are usually required for the building inadequacies observed in one iteration and are corrected and followed by another. This iterative investigation and design process continues until the design is satisfied by pre established performance criteria. The performance criteria for pushover investigation are generally established as the required state of the structure given in roof top or spectral displacement amplitude. Static Non-linear Analysis procedure, also called as sequential yield investigation or simply "pushover analysis" which has significant popularity during few years pastly. 


\subsection{Bare Frame}

In bare frame buildings considered according to the current position of seismic analysis opposing design forces produced in the building during a major seismic analysis it exceeds the yielding ability of certain elements and causes huge in-elastic deformation. These deformation results from merged effects of lateral loads and gravity. These will be assembled in regions of maximum interior forces and are known as critical areas. Critical areas can be classified into distinct types depending on the interior forces which are produced in them and control their hysteretic activities. These types are areas subjected to flexure, areas subjected to flexure together with high shear forces and lastly areas subjected to flexure together with high axial and shear forces. Column-Beam intersections are critical areas which are subjected to large axial and shear forces. The forces produced in the distinct critical areas depend on the building system, the type of excitation of the building, the location of the critical area, and the ratio of length to depth of the member given.

\section{MODELING}

In the present study bare frame, frame with infill walls and monolithic RC frame is analyzed and designed for dynamic loads. The structure which has certain eccentricities and unsymmetric in plan was selected. Also the column sizes and sections were varied along the storey as in the case of original real life structure.

A 4 storey typical RC structure is considered for the analysis and to study its performance under seismic loads. The results are matched with the practical results obtained in CPRI Bangalore. The results are compared with the results of 7 and 10 storeys.

\subsection{Description of Model}

\section{Material Properties}

The material used for construction is Reinforced concrete with M-20 grade of concrete and fe-415 grade of steel. As per IS-456:2000 the relationship between stress-strain is given. Following are the material properties which are basic:

Steel Elasticity Modulus, Es $=21 * 10^{4} \mathrm{~N} / \mathrm{mm}^{2}$

Concrete Elasticity Modulus e, EC $=22.36068 * 10^{3} \mathrm{~N} / \mathrm{mm}^{2}$

Concrete characteristic strength, fck $=2 * 10 \mathrm{~N} / \mathrm{mm}^{2}$

Steel yield stress, fy $=41.5 * 10 \mathrm{~N} / \mathrm{mm}^{2}$

Ultimate bending strain, $\delta \mathrm{cu}=0.00035 * 10$

\subsection{Model Geometry}

The structure analyzed is a four-storied, one bay along $\mathrm{X}$ direction and one bay along $\mathrm{Y}$-direction moment-resisting frame of reinforced concrete with properties as specified above. Here floors of concrete are rigid modeled. The details of the model are given as:

story number $=4$
In X-direction bays Number $=1$

In Y-direction bays Number=1 Storey

height $=4.0$ meters

Bay width along X-direction $=5.0 \mathrm{~m}$ Bay

width along $\mathrm{Y}$-direction $=5.0 \mathrm{~m}$

\section{RESULTS AND DISCUSSIONS}

Table -1: Base Shear Variations For Four Storey

\begin{tabular}{|c|c|c|c|c|}
\hline & Zone 2 & Zone 3 & Zone 4 & Zone 5 \\
\hline Bare & 63.56 & 101.7 & 152.56 & 228.83 \\
\hline MI & 100.4 & 160.63 & 240.95 & 361.43 \\
\hline RCC & 158.03 & 252.86 & 379.28 & 568.93 \\
\hline
\end{tabular}

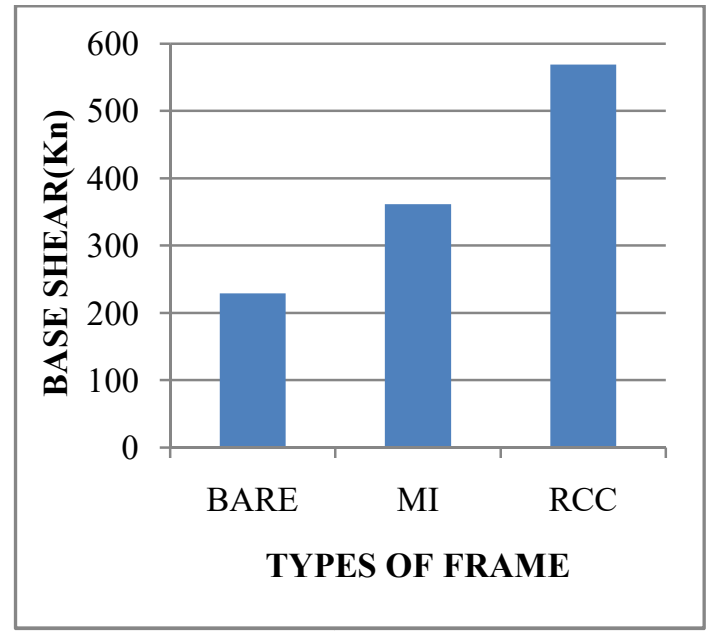

Fig - 1: Base Shear values for zone 5

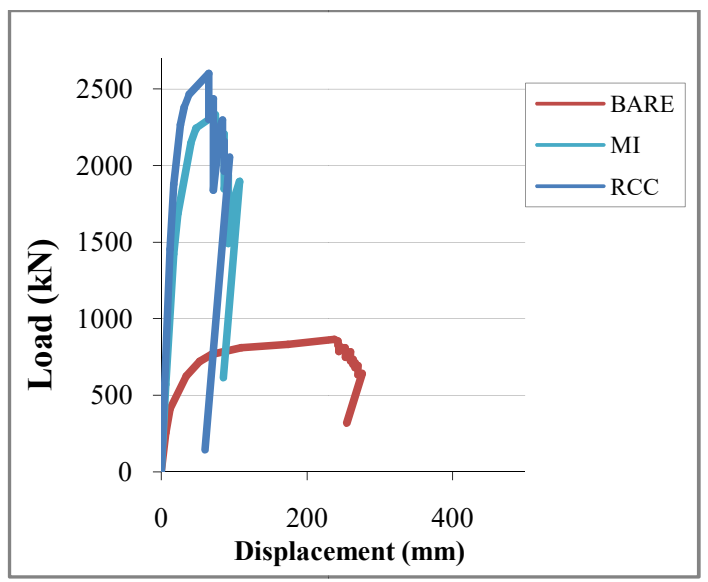

Fig - 2: Pushover curves for 4 storey frame

Table - 2: Base Shear Variations For For Seven Storey

\begin{tabular}{|l|l|l|l|}
\hline & Bare & $\begin{array}{c}\text { With } \\
\text { Masonry } \\
\text { infill }\end{array}$ & $\begin{array}{c}\text { With } \\
\text { RCC } \\
\text { infill }\end{array}$ \\
\hline Mode 1(Y-Direction) & 1.2333 & 2.1872 & 1.9841 \\
\hline Mode 2(X-Direction) & 1.5011 & 2.4455 & 2.3463 \\
\hline Mode 3(Torsion) & 1.9083 & 3.808 & 3.4831 \\
\hline
\end{tabular}




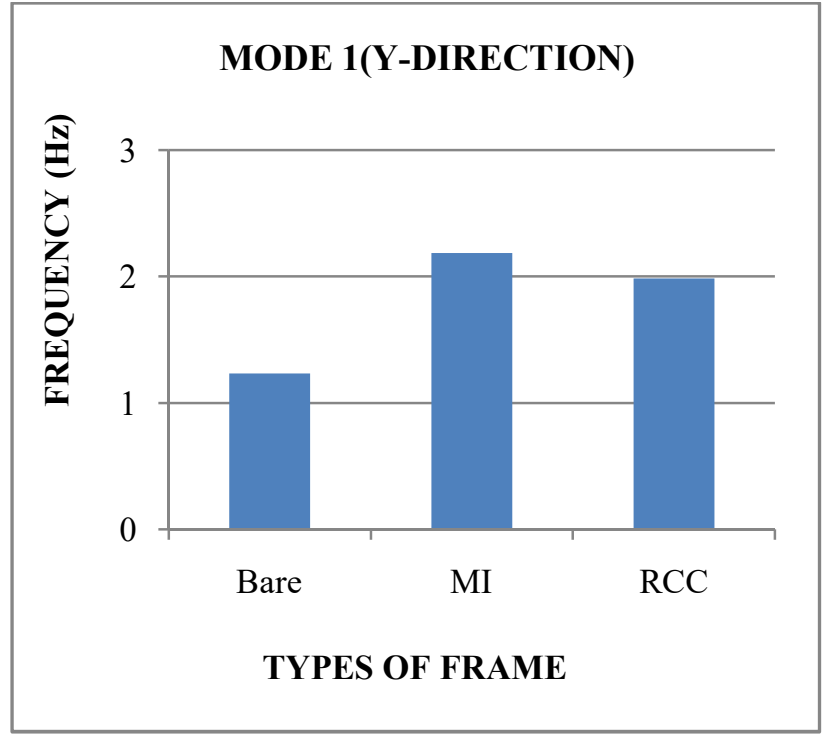

Fig - 3: Frequency of the frame in Mode 1(Ydirection)

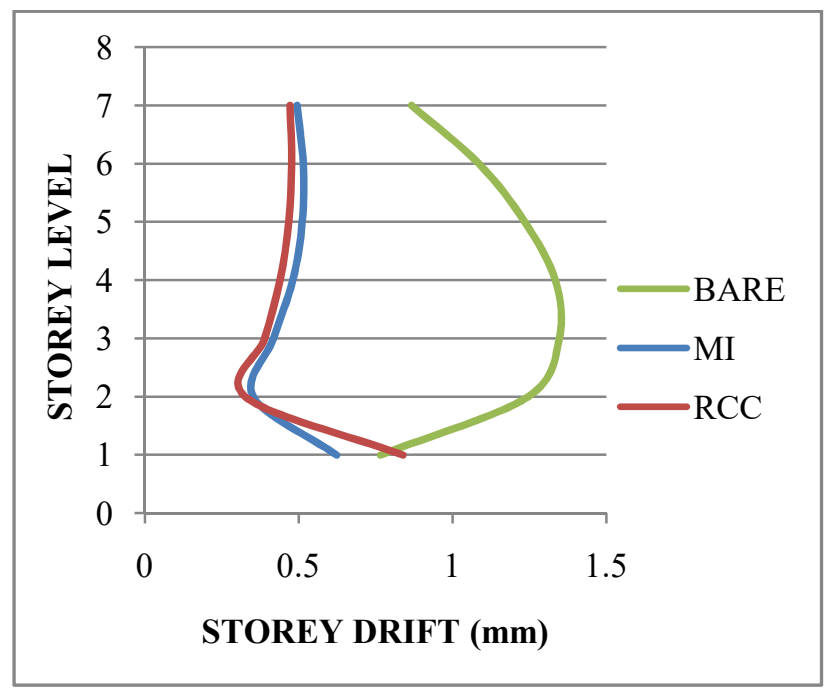

Fig - 4: Storey drift in X-direction for zone 5

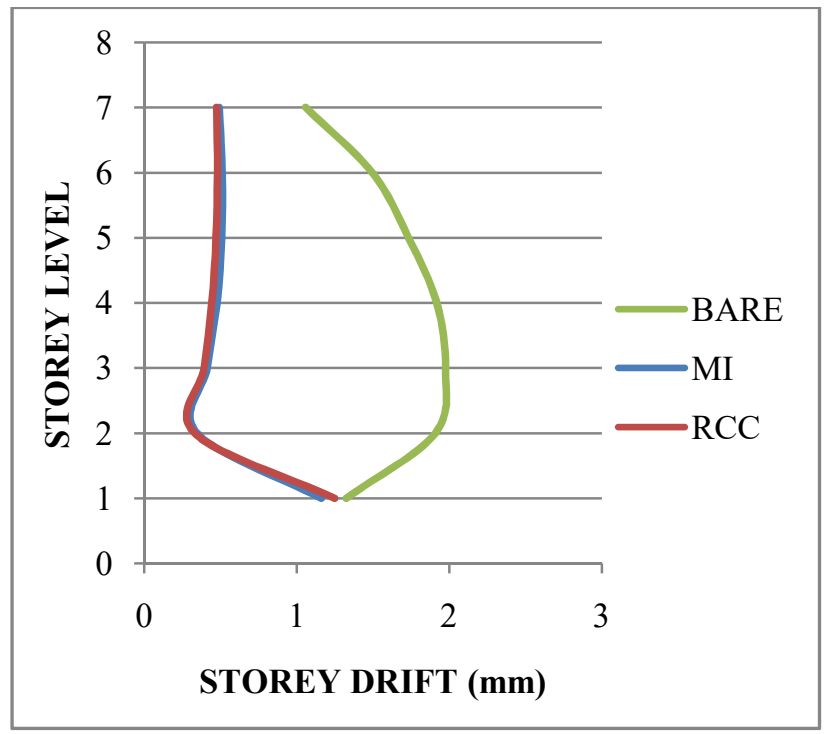

Fig - 5: Storey drift in Y-direction for zone 5

\begin{tabular}{|l|c|c|c|}
\hline Table - 3: Base Shear Variations For Ten Storey \\
\hline & Bare & $\begin{array}{c}\text { with } \\
\text { masonry } \\
\text { infill }\end{array}$ & $\begin{array}{c}\text { With } \\
\text { RCC } \\
\text { infill }\end{array}$ \\
\hline Mode 1(Y-Direction) & 0.8028 & 1.3296 & 1.2696 \\
\hline Mode 2(X-Direction) & 0.9478 & 1.3894 & 1.3749 \\
\hline Mode 3(Torsion) & 1.2981 & 2.8735 & 2.6709 \\
\hline
\end{tabular}

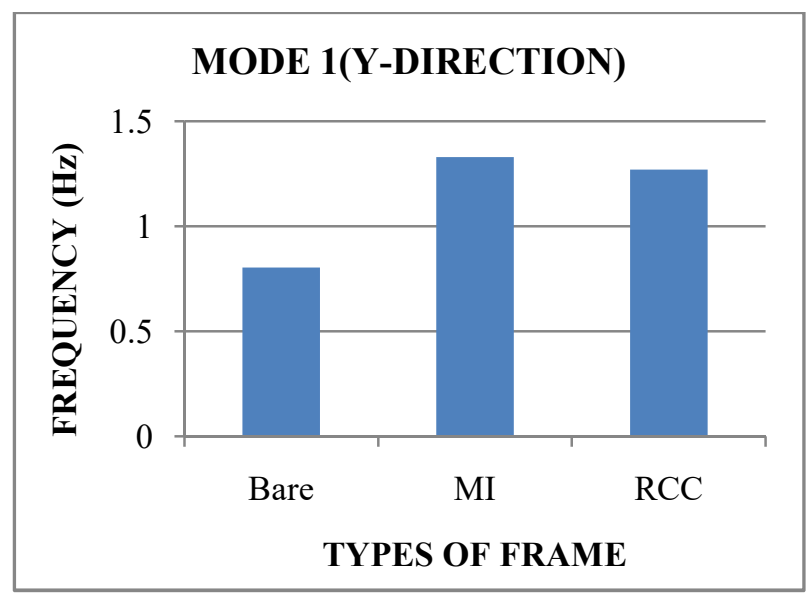

Fig - 6: Frequency of the frame in Mode 1(Y-direction)

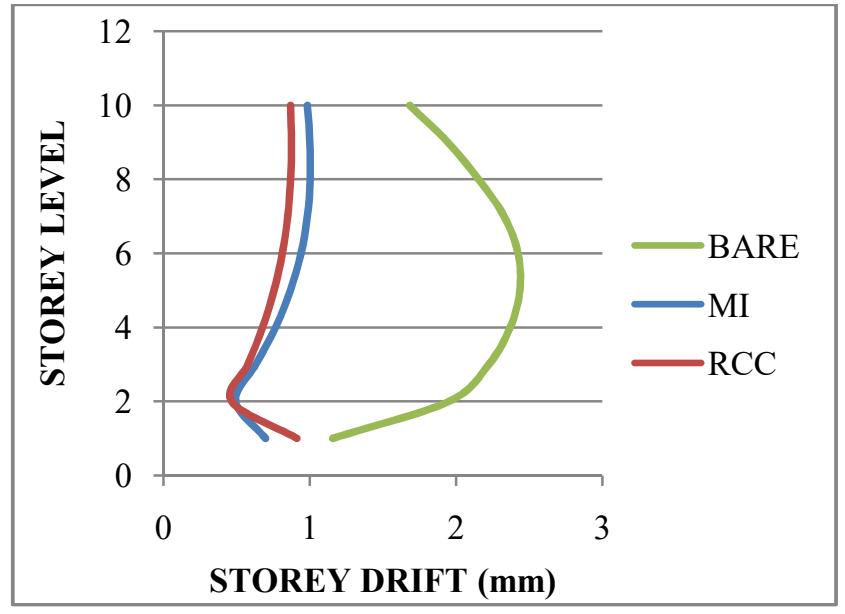

Fig - 7: Storey drift in X-direction for zone 5

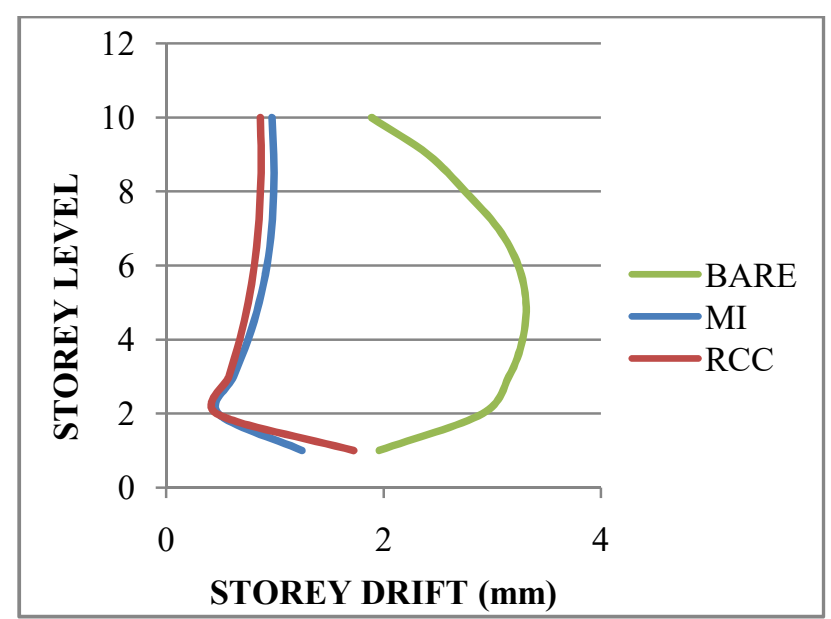

Fig - 8: Storey drift in Y-direction for zone 5 


\section{CONCLUSION}

D Detailed literature review on RCC infill and masonry infill frame as a lateral load resisting system and modeling of masonry infill as an equivalent diagonal strut are brought.

$>$ Modeling ofmasonry infill as equivalent diagonal strut adds stiffness and strength to the structure.

> Modal analysis is done for all models and corresponding natural frequency are obtained. Natural frequency increases with increase in stiffness so natural frequency is more for masonry infill frameand rcc infill frame compare tobare frame because of having high stiffness.

$>$ Equivalent static analysis is carried out for all models and corresponding base shearand storey shears are obtained. Base shear is directly proportional to self weight of the structure. Base shear and storey shear is high for rcc infill framewhen compared to bare and masonry infill frame because self weight of the structure is more.

$>$ Storey drift increases with increases in number of storeys and it reaches peak and again it decreases with increases in number of storey in case of bare frame. And in the case of masonry and rcc infill frame storey drift is more at storey 1 because of soft storey

> From pushover analysis results the resistance of the structure to base force and displacement of the structure to corresponding base force is determined. Rcc infill frame resist more base force and bare frame resist less base force. And displacement is more in bare frame compared to masonry infill and rcc infill frames.

$>$ When the number of storeys is increased the resistance of the structure to base force decreases and displacement increases.

> Masonry infill and rec infill structures are also found to be good lateral load resisting system compare to bare frame.

\section{REFERENCES}

[1] Modal investigation, investigation on damping of a host structure induced by attached cables Jiduck choi and Daniel $\mathrm{j}$ inman

[2] Descriptive study of pushover analysis in rec structures of rigid joint yousuf dinar, MD imam hossain, rajib kunar biswas, MD masud rana

[3] Seismic analysis from Wikipedia,historic developments in the evolution of earthquake by Robert Reitherman, curee.P12

[4] Seismic analysis of multi-storeyed buildings International journals by MN Patil

[5] Scholarity articles the EM side channel the sarbanese act of 2002 ,Pankaj et al.,(2002) 